\title{
Cardiopulmonary resuscitation (CPR) complications encountered in forensic autopsy cases
}

Aspasia Deliliga, Fotios Chatzinikolaou, Dimitrios Koutsoukis, loannis Chrysovergis and Polychronis Voultsos ${ }^{*}$

\begin{abstract}
Background: Cardiopulmonary resuscitation (CPR) provides a significant increase in survival rate, even if performed by bystanders. However, bystanders may refrain from performing CPR for fear of eventual malpractice litigation. Currently lack Guidelines specifying whether a particular CPR-related complication is in all likelihood unavoidable or not. To fulfill this gap a great number of studies is required to be published in the most relevant leading academic literature. This paper aims at making a contribution to addressing such a challenge.

Methods: A retrospective observational study based on forensic autopsy material aiming at recording injuries resulting from the application of CPR. The severity of injuries was forensically evaluated.

Results: Out of 88 cases autopsied, only $26.7 \%$ had rib fractures (only $20 \%$ of which were located in the 6 lower ribs), $17.4 \%$ had sternal fractures $(85.7 \%$ of which were detected in the body of the sternum and $14.3 \%$ in the manubrium). The ratio of sternal fractures to rib fractures is similar to the ratio cited in other studies reported in the literature (2:3, approximately). The number of fractures was 7.86 (4.11 on the right side and 4.75 on the left side). $16 \%$ of the cases were found to be mild, $48 \%$ were moderate, and $35 \%$ of the cases were severe. When a physician was present, a (not statistically significant) trend towards more severe complications was found.

Conclusion: The findings are in accordance with other similar studies reported in the literature referring to the classic external CPR. This study offers a proposal aiming at making a contribution to develop Guidelines specifying whether a particular CPR-related complication is in all likelihood unavoidable or not.
\end{abstract}

Keywords: Cardiopulmonary resuscitation, (un) avoidable CPR-related complications, Rib fractures, Sternal fractures

\section{Background}

Cardiopulmonary Resuscitation (CPR) constitutes one of the most important interventions at the socio-medical level. It is a simple procedure which, however, may result in significant increase of the rate of survival of patients who experience sudden cardiac arrest mostly due to coronary heart disease [1].

In case of cardiac arrest resuscitation attempts should continue until adequate spontaneous circulation is achieved or until the death of the patient is ascertained [2]. Nevertheless, these attempts may cause considerable injuries to patients, thus increasing rescuer's exposure to legal risk [2].

\footnotetext{
* Correspondence: voultsop@otenet.gr

Department of Forensic Medicine \& Toxicology, School of Medicine, Aristotle University of Thessaloniki, (Campus), School of Medicine, 54124 Thessaloniki,
} Greece

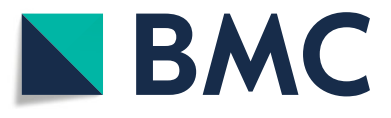

(c) The Author(s). 2019 Open Access This article is distributed under the terms of the Creative Commons Attribution 4.0 International License (http://creativecommons.org/licenses/by/4.0/), which permits unrestricted use, distribution, and reproduction in any medium, provided you give appropriate credit to the original author(s) and the source, provide a link to the Creative Commons license, and indicate if changes were made. The Creative Commons Public Domain Dedication waiver (http://creativecommons.org/publicdomain/zero/1.0/) applies to the data made available in this article, unless otherwise stated.
The injuries associated with the application of CPR are classified according to their incidence [2] and localization [3-6]. Interestingly, there are several publications reporting rare complications of CPR concerning both adults and minors [7-14].

According to the official website of the American Heart Association (AHA) [15], cardiac arrest is more frequent than the general public considers, and it may happen to anyone and at any time. Therefore, CPR training should not only be worthy of medical and paramedical staff's concern, but also it should be considered worthy of anyone's concern. According to the same source, four out of every five cases of cardiac arrest occur at home; thus, it is probable that a potentially life-saving CPR would be performed by a family member [15]. 
Despite the fact that the potential beneficial effect of CPR has been established, less than one out of three victims of out-of-hospital cardiac arrest receives life-saving assistance from a bystander [16].

CPR has been described as "violent, painful and undignified" [17]. However, it must be applied to all patients since it provides a 4-fold increase in survival rate, even if it is performed by bystanders [1].

Although out-of-hospital cardiopulmonary resuscitation (CPR) may result in a significant increase in survival rate even if it is performed by bystanders, certain CPR-related complications are unavoidable and, hence, bystanders in all likelihood may refrain from performing CPR for fear of eventual malpractice litigation even in jurisdictions where Samaritan laws are present. Currently lack Guidelines specifying whether a particular CPR-related complication is in all likelihood unavoidable or not. To fulfill this gap a great number of studies is required to be published in the most relevant leading academic literature. This paper aims at making a contribution to address such a challenge.

\section{Methods}

\section{Study design}

The purpose of this study was to record the incidence, localization, and severity of complications of CPR among individuals who did not survive their cardiac arrest in Thessaloniki (the second largest city in Greece) and associate them with the conditions under which CPR was performed, on the basis of our forensic autopsy findings. Precise assessment of the complications of CPR can only be made using forensic autopsy, since in most cases these injuries go radiologically undiagnosed [18]. This is the first study based on forensic autopsy material coming from Greece aiming at recording injuries resulting from the application of cardiopulmonary resuscitation. All the victims of cardiac arrest included in our study had undergone manual cardiopulmonary resuscitation. No one of them had undergone CPR including a mechanical chest compression device.

The records of 184 autopsies carried out in the Laboratory of Forensic Medicine and Toxicology of Aristotle University of Thessaloniki during a 12-month period in 2013 were examined. The study included all cases of violent and sudden deaths where CPR was performed.

Overall, 88 cases were included in the study. Our data involved demographic data, cause of death, type of death, number and skillfulness or experience of persons who performed CPR, presence and localization of soft tissue injuries, presence and localization of rib and sternal fractures, medications received, and location where CPR was performed. In cases where injuries due to CPR were identified, their severity was estimated forensically. Characterization of a category as "severe" neither corresponds to the "severe bodily injury" described in the Greek Penal Code (article 310), which refers to a life-endangering injury, nor to any other similar distinctions found in the international literature (e.g., at least 14 day hospitalization, or significant disability for at least 28 days) [19]. The injuries were classified into three categories (mild, moderate, severe) based on localization (proximity to the heart), number of fractured ribs (more or less than 6), history of medication interfering with the coagulation mechanism (factor which is also taken into consideration in other similar studies), and medical history, i.e., factors increasing the risk of complications. Whenever the number of fractures (with or without bleeding) was less than 6 , injuries were considered mild. When the number of fractures ranged from 7 to 12 , injuries were considered moderate, and when it ranged from 13 to 24, injuries were considered severe. The standard of "six fractured ribs" might be viewed as an arbitrary criterion, provided that the criteria used for classification of chest injuries depend on the criterion of 3 fractured ribs and on the clinical picture of the so-called "flail chest" (Open injury scaling, Chest Wall) [20], which, however, is absent in our necrotomic matter. Indeed, the classification into three categories (mild, moderate, severe) is not based on «gold standard». However, in our opinion a severity criterion necessarily involves a degree of arbitrariness. For instance, such a criterion should take into account both the number and the location of the injuries, provided that one only rib fracture located on the left half thorax and close to the heart may most likely lacerate it, even though, a greater number of rib fractures located on the right half thorax might be regarded as life-threatening injuries to a much lesser extent. We set our severity standards based on our forensic evaluation.

\section{Statistical analysis}

Values are expressed as mean \pm standard deviation (SD) or percentages. The independent samples t-test was employed for the comparison of means between groups. Pearson's chi-squared test was used to check the independence between categorical variables. Logistic regression was used for the assessment of the impact of age on the occurrence of rib fractures. $P$ values less than 0.05 were considered statistically significant. Statistical analysis was performed using SPSS v21.0 (IBM Corp, Armonk, NY). One-way analysis of variance was used to check differences between means of age for the different categories of injury severity.

\section{Results}

The bodies were those of 53 males and 35 females. At the time of death the age range was $18-87$ years $(60.6 \pm 7.5$ years). Cardiovascular diseases were the most common 
cause of death $(n=62)$ and most deaths were non-violent $(n=76)$. There was no chest injury prior to the cardiac arrest in none of the cases. All the identified injuries were due to performance of CPR.

\section{Incidence and location of the injuries}

All the CPR-related rib fractures involved in our autopsy findingswere located in (or very close to) the midclavicular line. As regards the CPR-related sternal fractures, $85.7 \%$ of these injuries were identified in the body of the sternum and $14.3 \%$ in the manubrium.

More specifically, out of 88 cases, only $26.1 \%$ had rib fractures. Most of them were located in the six upper ribs. The most common location of the fractures was the 2nd rib (in 39\% of them bilaterally). In $8,6 \%$ of them a fracture of the 1st rib was co-existed. Moreover, 17.4\% were accompanied with sternal fractures. Most of them were located in the body of the sternum (85.7\%). Results are summarized in Table 1.

As regards soft tissue injuries, $18.2 \%$ of cases were accompanied with soft tissue injuries, mostly identified on the left side (Table 2).

A history of osteoporosis was only found in one case; however, no CPR-related injuries were identified.

All cases with sternal fractures referred to a single fracture.

\section{Statistical correlations}

Statistical analysis showed independence between gender and rib or sternal fractures $(p>0.999$ and $p=0.819$, respectively).

Similarly, no correlation between age and rib or sternal fractures was found ( $p=0.290$ and $p=0.533$ respectively).

\section{Who performed CPR and where}

In $96.6 \%$ of the cases, CPR was performed by specialized staff (medical, paramedical or both), and in $2 \%$ of the cases it was performed by both specialists and laypersons. As regards the specialized staff, in $52.3 \%$ of the cases it was paramedical staff, in about $20 \%$ of the cases it was medical staff, while a coexistence of medical and paramedical staff was reported in $28 \%$ of the cases, approximately. In $29.1 \%$ of the cases, more than one

Table 1 Rib fractures (RF) location in association with sternal fractures (SF)

\begin{tabular}{lllll}
\hline Right side RF & Left side RF & Sternal fractures (SF) & Incidence & N \\
\hline$\checkmark$ & $\checkmark$ & $\checkmark$ & $37 \%$ & 10 \\
$\checkmark$ & $\checkmark$ & - & $29,6 \%$ & 8 \\
$\checkmark$ & - & $7,4 \%$ & 2 \\
- & - & - & $7,4 \%$ & 2 \\
- & $\checkmark$ & $\checkmark$ & $3,7 \%$ & 1 \\
- & $\checkmark$ & $\checkmark$ & $14,8 \%$ & 4 \\
\hline
\end{tabular}

Table 2 Soft tissue injuries

\begin{tabular}{llll}
\hline Right side & Left side & Incidence & N \\
\hline$\checkmark$ & - & $1,2 \%$ & 1 \\
- & $\checkmark$ & $10,6 \%$ & 11 \\
$\checkmark$ & $\checkmark$ & $7,1 \%$ & 6 \\
\hline
\end{tabular}

person actively participated in the procedure (see Table 3). A physician was present in $47.7 \%$ of the cases. More severe injuries were more often found in cases where CPR was performed in the presence of a physician and in presence of more than one other person, although without statistical significance $(p=0.59$ and 0 +.195 , respectively). Whenever a physician was present, injuries were moderate or severe at equal frequency (see below), but they were never mild. In addition, in $58 \%$ of cases where CPR was performed in the presence of a physician, there was a second person present in the area as well, which complicates the interpretation of this finding. It is possible that the trend towards more severe injuries in the presence of a physician is either due to a more intensive application of CPR by the physician, or to a repetitive application of CPR (e.g., the physician arrives at the area at a later stage and repeats the procedure).

The place where CPR was performed was the victim's home in $27.3 \%$ of the cases, a public place in $22.7 \%$, and a medical environment in $46.6 \%$ of the cases. This means that, in $50 \%$ of the cases, CPR was performed in out-of-hospital settings.

\section{The severity of injuries}

None of the identified CPR-related injuries was lethal. The severity of injuries was evaluated in the aforementioned cases and it was found that $16 \%$ of them were mild, $48 \%$ were moderate, and $35 \%$ of the cases were severe. When CPR was performed by more than one person, the injuries were moderate or severe at an equal rate and they were never mild, whereas when it was performed by a single person, in $23.8 \%$ of the cases it resulted in mild injuries, in $47.6 \%$ it resulted in moderate injuries, and in $28.6 \%$ it caused severe injuries (See Table 4). Statistical analysis showed no association between severity of injuries and gender (chi-square $=1.022$, $\mathrm{df}=3, p=0.796$ ) (see Table 5 and Table 6 ). In addition, it was established that there is some independence between severity of injuries and type of staff (chi-square $=7.398, \mathrm{df}=6, p=0.286$ ) and also between severity of injuries and place where CPR was performed (chi-square $=8.614, \mathrm{df}=9, p=0.474)$.

\section{Discussion}

The major finding of this study were that the incidence of rib and sternal fractures and of soft tissue injuries 
Table 3 Number of rescuers

\begin{tabular}{llllcr}
\hline & & Frequency & Percent & Valid Percent & Cumulative Percent \\
\hline Valid & 1 Person & 61 & 69,3 & 70,9 & 70,9 \\
& $>1$ Persons & 25 & 28,4 & 29,1 & 100,0 \\
Missing & Total & 86 & 97,7 & 100,0 & \\
Total & 99 & 2 & 2,3 & & \\
\hline
\end{tabular}

caused by $\mathrm{CPR}$ is consistent with the corresponding rates of other studies $[3,5,6,18]$ The ratio of rib to sternal fractures was similar to the ratio cited in other studies $[3,5,6,18]$.

A wide range of incidence rates of rib fractures caused by CPR (13-97\%) [21] has been reported in the literature. Sternal fractures are reported at a rate usually ranging from 14 [3] to 30\% [22] even though frequencies as low as $1 \%$ and as high as $43 \%$ are also reported [21]. Lederer et al. reported rib and sternal fractures at a rate of $94.7 \%$ following a successful CPR procedure [18]. In a forensic research conducted by the University of Edinburgh, which included 499 cases, Black et al. reported rib fractures in $29 \%$ of the cases (concerned mainly females) and sternal fractures in 14\% of the cases [3]. The incidence of sternal fractures reported by various authors is almost by half compared to the reported incidence of rib fractures [3]. Rib fracture incidence was positively associated with advanced age. In 97 cases, where there were "multiple" rib fractures, no significant difference was found between right (4 ribs) and left side (4 ribs) [3]. In our study the average fractures were 7.86 overall (4.11 on the right side and 4.75 on the left side). A Turkish study (University of Pamukkale) including 231 deaths, reported an incidence rate of $13.2 \%$ for rib and sternal fractures [6]. Rabl et al. report an incidence rate of $28 \%$ for rib fractures and $16 \%$ for sternal fractures [23]. Similarly, Baubin et al. reported incidence rates of 55 and 30\% [22], and Black et al. reported incidence rates of 29 and 14\%, respectively [3]. Out of 96 autopsies overall, Hashimoto et al. reported incidence rates of $52 \%$ ( $43 \%$ on the right side, $48 \%$ on the left side, and 39\% bilaterally) and 39\%, respectively (only 9\% of which was not accompanied by rib fractures) [5]. The average fractured ribs were 7.3 depending on the case. Hoke and Chamberlain report incidence rates of 13-97\% and $1-43 \%$, respectively, while they report almost zero incidence rates for children [21]. It is maintained in the literature that females have sternal fractures more frequently (since they have smaller and thinner sternum) [24], as well as that the elderly are at higher risk for rib fractures [25]. The incidence of rib fractures increases with age. However, this is not the case with sternal fractures [3]. Both rib and sternal fractures are rare among persons under 20 years of age [5]. Rib and sternal fractures are reported far more rarely in infants and children. Rib fractures often occur at the 3rd, 4th, or 5th rib, located in the midclavicular line of the rib cage [4]. However, in $60 \%$ of our cases with rib fractures was found a fracture of the 2nd rib.

Accordingly, sternal fractures occur most frequently in the region between the level of 3rd and 4th rib, or between the level of 4th and 5th rib [4]. Interestingly, Krischer et al. maintain that fractures in these regions might be considered unavoidable [4]. In $20 \%$ of their cases, they identified some avoidable fractures (at very high or very low ribs, at a rate of $5 \%$ at both high and low ribs). They report a rate of $4 \%$ for sternal fractures. A high incidence rate of fractures at the first and, mostly, at the second rib, even bilaterally, was found in our study. In no one of our case was found other CPR-related complication such as pericardial, pulmonary, cardiac trauma or thrombosis. Visceral injuries as

Table 4 Number of rescuers and evaluation of injuries severity

\begin{tabular}{|c|c|c|c|c|c|}
\hline & & & \multicolumn{2}{|c|}{ Rescuers number } & \multirow[t]{2}{*}{ Total } \\
\hline & & & 1 person & $>1$ persons & \\
\hline \multirow{6}{*}{$\begin{array}{l}\text { FForensic Evaluation } \\
\text { of Severity }\end{array}$} & \multirow[t]{2}{*}{ Mild } & Count & 5 & 0 & 5 \\
\hline & & Percent & $23,8 \%$ &, $0 \%$ & $16,1 \%$ \\
\hline & \multirow[t]{2}{*}{ Moderate } & Count & 10 & 5 & 15 \\
\hline & & Percent & $47,6 \%$ & $50,0 \%$ & $48,4 \%$ \\
\hline & \multirow[t]{2}{*}{ Severe } & Count & 6 & 5 & 11 \\
\hline & & Percent & $28,6 \%$ & $50,0 \%$ & $35,5 \%$ \\
\hline \multirow[t]{2}{*}{ TTotal } & & Count & 21 & 10 & 31 \\
\hline & & Percent & $100,0 \%$ & $100,0 \%$ & $100,0 \%$ \\
\hline
\end{tabular}


Table 5 Gender and rib fractures (RF)

\begin{tabular}{|c|c|c|c|c|c|c|}
\hline & \multicolumn{6}{|c|}{ Cases } \\
\hline & \multicolumn{2}{|c|}{ Valid } & \multicolumn{2}{|c|}{ Missing } & \multicolumn{2}{|c|}{ Total } \\
\hline & $\mathrm{N}$ & Percent & $\mathrm{N}$ & Percent & $\mathrm{N}$ & Percent \\
\hline Gender of victims with RF & 86 & $97,7 \%$ & 2 & $2,3 \%$ & 88 & $100,0 \%$ \\
\hline
\end{tabular}

well as dangerous air embolism after cannulation of the external jugular vein are considered rare complications. In addition, bone marrow embolism may be seen in peripheral vessels. It is reported in $13 \%$ of the cases [5].

The results of our study are consistent with the findings of other studies showing that there is no difference in the incidence rate of adverse effects when comparing a specialized staff with laypersons [26]. However, Kim et al. showed that the presence of non-physician chest compressors in the Emergency Department was one of the contributing factors to the formation of rib fractures [27].

The here presented findings might contribute on the enrichment of literature concerning CPR-related rib and sterna fractures. Interestingly, the greater the number of cases in literature with CPR-related rib and sternal fractures, the more reliable the consideration that certain CPR-related rib or sternal fractures were unavoidable, namely, should normally not raise malpractice litigation. Not surprisingly, it has been established that the adequate depth of chest compression is a matter of the utmost importance for an increase in the possibility of achieving spontaneous circulation. The European Resuscitation Council (ERC) has changed their recommendation about minimal compression depth from $40 \mathrm{~mm}$ (2005) to $50 \mathrm{~mm}(2010)[28,29]$. The quality of chest compressions has improved significantly after the 2010 AHA guidelines; however, it is more difficult for the rescuer to comply with the guidelines because of increased fatigue in long duration CPR [30].

According to Hellevuo et al. iatrogenic injuries increase as compression depth exceeds $6 \mathrm{~cm}$, especially in case of male patient. However, it is worth noting that the injuries are characterized "by and large not fatal" [31].

Below, we go into some details concerning eventual CPR-related liability. It is widely accepted that when performing CPR, certain complications are ordinary and unavoidable, even if CPR was performed lege artis and with the due diligence. The physician performing CPR is aware of these complications and accepts their occurrence

Table 6 Gender and rib fractures (RF)

\begin{tabular}{lllll}
\hline & & \multicolumn{2}{l}{ Rib fractures } & Total \\
\cline { 3 - 4 } & & Yes & No & \\
\hline Gender & Male & 14 & 37 & 51 \\
& Female & 9 & 26 & 35 \\
Total & 23 & 63 & 86 \\
\hline
\end{tabular}

as necessary or, at least, as potential. This means - at least according to Greek and German Criminal Law that there is some indirect "intent" (Intend Second Degree, namely, the physician knows that a certain incidental-perhaps undesired-consequence will occur) or conditional intent (Intend Third Degree, namely, the physician foresees the result as possible and accept it, albeit undesired) [32, 33]. Other complications, however, may be (fully or partially) due to an incorrect medical procedure (e.g., incorrect placing of the hands on the chest, excessive pressure force, etc.). Such complications are hard to distinguish from unavoidable complications. Such distinction is still immature both in theory/legal doctrine and in case-law. Nevertheless, such distinction is of vital importance whenever an issue of medical liability arises. The characterization of any complications as unavoidable may discharge a physician from liability. Either in the context of the existing negligence-based legal system or in an alternative (reform) legal system, e.g. a "no-fault" compensation system [19]. Under the Greek legal framework both civil and criminal liability may arise for a physician who has performed CPR. Article 29 of the Greek Penal Code (PC) along with article $310 \$ 1$ PC provide for a sentence for a severe unintentional bodily injury whose outcome is due to negligence (of rescuer in the instance of CPR).

Not surprisingly, there is a "grey zone" between avoidable and unavoidable CPR complications. However, there is a "core" of complications which may be considered "unavoidable" almost with certainty. Such complications can be determined based on forensic studies which promise more reliable results and involve a larger number of cases provided that spontaneous circulation and hemodynamic stability is attainable in only a small number of cases.

Our study is an attempt to contribute to determining the rib and sternum CPR-related injuries that might be viewed as "in all likelihood unavoidable". Only classic osseous injuries of the ribs and sternum were identified at a frequency similar to that reported in other studies, i.e. as regards their locations. There was no correlation with factors such as gender, age, place where CPR is performed, or rescuer. This conclusion is considered to favour the classification of particular bone injuries among the unavoidable complications. However, it is crucial to bear in mind that it would be a difficult task to accurately determine the incidence of CPR-related rib and sternal fractures. Further research is needed in this perspective. Miller et al. arguably state that "the incidence of reported CPR-associated cardiovascular and thoracic wall injuries varies widely" [34]. The authors put it best in saying that "this may reflect several factors including the quality of the chest compressions and $\mathrm{CPR}$, the diligence in defining these complications in 
survivors and non-survivors and the varying sensitivity of different diagnostic modalities to detect these injuries" [34]. Takayama et al. recently argue that "long duration of out-of-hospital CPR was an independent risk factor for chest injuries, possibly due to the difficulty of maintaining adequate quality of CPR." [35]. Kralj et al. showed that "increased compression rate and depth cause more skeletal chest injuries (SCI)" [36]. Although "it is generally considered that at least $1 / 3$ of resuscitated patients sustain rib fractures and at least 1/5 sustains sternum fractures", Kralj et al. showed that these injuries are much more frequent [36].

\section{Conclusion}

In accordance with other similar studies reported in the literature referring to the classic external CPR it is considered that rib and sternal fractures located at the 3rd, 4th, and 5th ribs and at the corresponding part of the body of the sternum, not extending beyond the midclavicular line of the rib cage, might possibly be described as unavoidable injuries. This consideration presupposes that the average rib fractures should not exceed 7 or 8 , with almost equal bilateral distribution (with a slight deviation for the left side). Besides, the ratio sternal fractures: rib fractures should be equal to the fraction $2 / 3$ (approximately).

\section{Proposition}

In our opinion, the findings of our study which are in accordance with the available relevant literature encourage further research in the perspective of confirming the following Guideline:

In case of adult patients, the following complications might be classified as unavoidable:

A) Rib fractures (of 3rd, 4th, or 5th rib) which do not extend beyond the midclavicular line of the rib cage;

B) The total number of which does not exceed 6 fractures;

C) There is almost equal distribution of right- and leftsided rib fractures, with a slight deviation for the left side;

D) There is one or two sternal fractures at a level corresponding to the 3rd-5th rib.

Note, however, that osteoporosis or any other anatomical variation of the chest should not be present. These are elements that must be considered in the forensic medical examination on a case-by-case basis.

It is also suggested that more rigorous forensic investigations (involving the consideration of the detailed anatomical and histological variations of any given chest wall, eventually using ad hoc models of CPR) is needed for greater certainty on the location and the number of fractures that might be regarded as "in all likelihood unavoidable complications".

Our proposal aims at making a contribution to develop Guidelines specifying with high degree of certainty whether a particular CPR-related complication is in all likelihood unavoidable or not.

These Guidelines are expected to prevent potential rescuers from practicing "negative defensive medicine" in the context of emergency medicine in terms of avoiding the performance of CRP due to fear of malpractice litigation. At any rate, it is crucial to bear in mind that those who provide emergency medical service should be secured "potential to provide better public service" [37].

\section{Limitations}

We have no data on CPR duration. Provided that the longer the duration of CPR was, the greater the number of CPR-related complications might be, lack of data concerning the duration of CPR is a limitation of our study. Another limitation of our study is that we have no data concerning the gender of the rescuers.

\section{Abbreviations \\ AHA: American Heart Association; CPR: Cardiopulmonary Resuscitation; ERC: European Resuscitation Council; PC: Penal Code}

\section{Acknowledgements}

Not applicable.

Funding

The authors declare no funding in this report.

Availability of data and materials

The datasets used and analysed during the current study are available from the corresponding author on reasonable request.

\section{Authors' contributions}

$A D$ and $P V$ have equally contributed to the manuscript. $A D, P V$ and $F C$, along with DK and IC conceptualised the study, carried out the literature review, conducted the analysis, interpreted the data, and drafted and critically reviewed the manuscript. All authors have read and approved the manuscript.

Ethics approval and consent to participate

The study was approved by the Ethics Committee of the School of Medicine of the Faculty of Health Sciences of Aristotle University, Thessaloniki, Greece (No: $1.43 / 21-11-2018)$.

Consent for publication

Not applicable.

Competing interests

The authors declare that they have no competing interests.

\section{Publisher's Note}

Springer Nature remains neutral with regard to jurisdictional claims in published maps and institutional affiliations. 
Received: 24 November 2018 Accepted: 18 February 2019

Published online: 28 February 2019

\section{References}

1. Stiell IG, Wells GA, Field B, Spaite DW, Nesbitt LP, De Maio VJ, et al. Advanced cardiac life support in out-of- hospital cardiac arrest. N Engl J Med. 2004:351:647-56.

2. Buschmann C, Tsokos M. Frequent and rare complications of resuscitation attempts. Intensive Care Med. 2009;35:397-404.

3. Black C, Busuttil A, Robertson C. Chest wall injuries following cardiopulmonary resuscitation. Resuscitation. 2004;63:339-43.

4. Krischer JP, Fine EG, Davis JH, Nagel EL. Complications of cardiac resuscitation. Chest. 1987:92:287-91.

5. Hashimoto H, Moriya F, Furumiya J. Forensic aspects of complications resulting from cardiopulmonary resuscitation. Legal Med. 2007:9:94-9.

6. Boz B, Erdur B, Acar K, Ergin A, Turkcuer I, Ergin N. Frequency of skeletal chest injuries associated with cardiopulmonary resuscitation: forensic autopsy. Ulus Travma Acil Cerrahi Derg. 2008;14(3):216-20.

7. Salzman M, Friedman J. Bystander cardiopulmonary resuscitation-induced splenic laceration and hepatosplenic hematoma. Am J Emerg Med. 2012; 30(2):388.

8. Camden JR, Carucci LR. Liver injury diagnosed on computed tomography after use of an automated cardiopulmonary resuscitation device. Emerg Radiol. 2011;18(5):429-31.

9. Custer JR, Polley TZ Jr, Moler F. Gastric perforation following cardiopulmonary resuscitation in a child: report of a case and review of the literature. Pediatr Emerg Care. 1987;3(1):24-7.

10. Machii M, Inaba H, Nakae H, Suzuki I, Tanaka H. Cardiac rupture by penetration of fractured sternum: a rare complication of cardiopulmonary resuscitation. Resuscitation. 2000:43:151-3.

11. Clinch SL, Thompson JS, Edney JA. Pneumoperitoneum after cardiopulmonary resuscitation: a therapeutic dilemma. J Trauma. 1983;23(5):428-30.

12. Gayle MO, Kissoon N, Hered RW, Harwood-Nuss A. Retinal hemorrhage in the young child: a review of etiology, predisposed conditions, and clinical implications. J Emerg Med. 1995;13(2):233-9.

13. Reardon MJ, Gross DM, Vallone AM, Weiland AP, Walker WE. Atrial rupture in a child from cardiac massage by his parent. Ann Thorac Surg. 1987;43(5):557-8.

14. Buschmann CT, Stenzel W, Martin H, Heppner FL, Guddat SS, Tsokos M. Calcified myocardial necrosis in pediatric patients after cardiopulmonary resuscitation. Forensic Sci Med Pathol. 2013;9:543-50.

15. American Heart Association. "CPR Statistics" in: http://www.heart.org/ HEARTORG/CPRAndECC/WhatisCPR/CPRFactsandStats/CPR-Statistics_UCM_ 307542_Article.jsp. Accessed 23 Feb 2019.

16. Nichol G, Thomas E, Callaway CW, Hedges J, Powell JL, Aufderheide TP, et al. Regional variation in out-of-hospital cardiac arrest incidence and outcome. JAMA. 2008;300:1423-31.

17. Gillon R. Resuscitation policies - action required. J Med Ethics. 1992;18:115-6.

18. Lederer W, Mair D, Rabl W, Baubin M. Frequency of rib and sterna fractures associated with out-of-hospital cardiopulmonary resuscitation is underestimated by conventional chest X-ray. Resuscitation. 2004;60:157-62.

19. Kachalia AB, Mello MM, Brennan TA, Studder DM. Beyond negligence: Avoidability and medical injury compensation. Soc Sci Med. 2008;66(2):387-402.

20. Moore EE, Cogbill TH, Jurkovich GJ, McAninch JW, Champion HR, Gennarelli TA, et al. Organ injury scaling. III: chest wall, abdominal vascular, ureter, bladder, and urethra. J Trauma. 1992;33(3):337-9.

21. Hoke RS, Chamberlain D. Skeletal chest injuries secondary to cardiopulmonary resuscitation. Resuscitation. 2004;63(3):327-38.

22. Baubin M, Sumann G, Rabl W, Eibl G, Wenzel V, Mair P. Increased frequency of thorax injuries with ACD-CPR. Resuscitation. 1999:41:33-8.

23. Rabl W, Baubin M, Broinger G, Scheithauer R. Serious complications from active compression-decompression cardiopulmonary resuscitation. Int J Legal Med. 1996;109:84-9.

24. Rabl W, Baubin M, Haid C, Pfeiffer KP, Scheithauser R. Review of active compression-decompression cardiopulmonary resuscitation (ACD-CPR). Analysis of iatrogenic complications and their biomechanical explanation. Forensic Sci Int. 1997:89:175-83.

25. Baubin M, Rabl W, Pfeiffer KP, Benzer A, Gilly H. Chest injuries after compression-decompression cardiopulmonary resuscitation (ACD-CPR) in cadavers. Resuscitation. 1999:43:9-15.

26. Oschatz E, Wunderbaldinger $P$, Sterz F, Holzer M, Kofler J, Slatin H, et al. Cardiopulmonary resuscitation performed by bystanders does not increase adverse effects as assessed by chest radiography. Anaesth Analg. 2001;93: 128-33.

27. Kim MJ, Park YS, Kim SW, Yoon YS, Lee KR, Lim TH, et al. Chest injury following cardiopulmonary resuscitation: a prospective computed tomography evaluation. Resuscitation. 2013;84(3):361-4.

28. Nolan JP, Soar J, Zideman DA, Biarent D, Bossaert LL, Deakin C, Koster RW, Wyllie J, Böttiger B, ERC Guidelines Writing Group. European Resuscitation Council Guidelines for Resuscitation 2010 Section 1. Executive summary. Resuscitation. 2010;81(10):1219-76.

29. Kampmeier TG, Lukas RP, Steffler C, Sauerland C, Weber TP, Van Aken H, et al. Chest compression depth after change in CPR guidelines-- improved but not sufficient. Resuscitation. 2014;85(4):503-8.

30. Yang Z, Li H, Yu T, Chen C, Xu J, Chu Y, et al. Quality of chest compressions during compression-only CPR: a comparative analysis following the 2005 and 2010 American Heart Association guidelines. Am J Emerg Med. 2014; 32(1):50-4.

31. Hellevuo H, Sainio M, Nevalainen R, Huhtala H, Olkkola KT, Tenhunen J, et al. Deeper chest compression - more complications for cardiac arrest patients? Resuscitation. 2013;84(6):760-5.

32. Psaroulis D, Voultsos P. Medical Law. Elements of Bioethics. Thessaloniki: University Studio Press; 2010. p. 36-7. [in Greek]

33. Krey V. German Criminal Law, Vol II. Stuttgart: Kohlhammer; 2003. para 338

34. Miller AC, Rosati SF, Suffredini AF, Schrump DS. A systematic review and pooled analysis of CPR-associated cardiovascular and thoracic Injuries. Resuscitation. 2014;85(6):724-31.

35. Takayama W, Koguchi H, Endo A, Otomo Y. The association between cardiopulmonary resuscitation in out-of-hospital settings and chest injuries: a retrospective observational study. Prehosp Disaster Med. 2018;33(2):171-5.

36. Kralj E, Podbregar $M$, Kejžar N, Balažic J. Frequency and number of resuscitation related rib and sternum fractures are higher than generally considered. Resuscitation. 2015;93:136-41.

37. Graham CA, Cheung CSK, Rainer TH. EMS systems in Hong Kong. Rescusitation. 2009:80(7):736-9.

\section{Ready to submit your research? Choose BMC and benefit from:}

- fast, convenient online submission

- thorough peer review by experienced researchers in your field

- rapid publication on acceptance

- support for research data, including large and complex data types

- gold Open Access which fosters wider collaboration and increased citations

- maximum visibility for your research: over 100M website views per year

At BMC, research is always in progress.

Learn more biomedcentral.com/submissions 